ever, was first, and it is called the Lebesgue integral. For tunately, Young's name is attached not only to recondite theorems in the theory of Fourier series and the theory of surfaces, but to more than one result in undergraduate analysis, where the clarity of his mind created a new simplicity and a new elegance.

He raised a large and talented family. He died in 1942, alone in Lausanne, separated by the accidents of war from his wife and family. At a seminar on November 5, at Imperial College, Sir Graham Sutton (one of Young's pupils), Dr. J. C. Burkill and Prof. J. Proudman spoke on Young and his mathematical work, including his methods of teaching, and the centenary was commemorated in the evening by a small dinner at his old club, the Athenaeum. (See also Nature, 150, 227; 1942.)

H. D. URSELI.

\title{
SHIFTING SAND BANKS OFF LOWESTOFT
}

L ITTLE is known about the origin or stability of sand banks although some are serious hazards to navigation around the southern half of the British Isles. Accordingly, publication of a detailed account of 6 square miles of sand banks off Lowestoft* is a most welcome addition to knowledge, for both practical and academic reasons. It is fitting that this study was carried out by a member of staff of the department of the Admiralty which surveys the sea-floor and draws up navigational charts.

The method of approach adopted by Mr. Cloet was to compare the 44 detailed surveys made between 1835 and 1962, using a standard datum. From these surveys he prepared figures showing the maximum and minimum depths detected at any place and then derived a further figure showing the maximum known changes in thickness which can be expected. Such changes may reach even as much as $80 \mathrm{ft}$. It is suggested that the channelled surface of maximum depth is made of bedrock or relatively immovable material such as pebbles.

* Admiralty : Hydrographic Department. Admiralty Marine Science Publications. No. 6: Hydrographic Analysis of the Sandbanks in the Approaches to Lowestoft Harbour. By $\mathrm{R}$. $\mathrm{L}$. Cloet. Pp. 1 il $+15+22$ illustra-
tions +12 graphs. (London: Admiralty, Hydrographic Department, 1963.)
Much of the analysis is concerned with a demonstration of the stability or motion of channels and sand banks and the smaller features associated with them. It is shown that the rate of movement of a feature need not be uniform and can vary with depth. Their direction of growth is particularly interesting since it is apparent that they approach Lowestoft both from north-northwest and south-south-west, and interfere off the harbour entrance. There are indications that their direction of growth corresponds to the direction of sand transport by tidal currents though the occasions of transport, and the relative importance of sea-waves cannot be revealed by such a study.

Diagrams are numerous, but it is a pity that so few are self-explanatory. It is rather unfair that only some of the localities mentioned in the text are shown on the figures, for not everyone has ready access to detailed Admiralty charts, or knows the region as well as Mr. Cloet. A much more serious criticism concerns the difficulty of identifying the ornament and of matching it with that in the key on figures, such as 3-5. Such a style of reproduction is false economy.
A. H. STrRIDE

\section{LONG-RANGE WEATHER FORECASTS}

$\mathrm{T}$ HE present state of knowledge does not permit a satisfactory theoretical solution to the problem of the general circulation of the atmosphere, nor to the associated problem of forecasting for long periods ahead. Because of the practical importance of long-range forecasts, many national meteorological services attempt to deal with the problem empirically, mostly on a regional basis and, of course, avoiding over-precision. No country depends entirely on one method of prediction, but makes the most of a variety of aids towards a solution. In any country, however, there tends to be a concentration of effort along particular lines because of the work involved. A short description of the methods adopted by different meteorological services has recently been published ${ }^{1}$ by the German Weathor Servico, following the report ${ }^{2}$ published in 1962 by a working group of the Commission for Aerology (World Meteorological Organization).

Some methods used are statistical and objective, and can treat a wide range of observational material in attempts to find correlations between future weather and available measurements. Regrossion oquations havo beon used, for example, in forecasting the Indian Monsoon, but simple and multiple corrolation tables also have their uses. The French, German and Russian weathor services make great use of statistical methods. The various chosen predictors may bo values of anomalies of pressure, temperaturo or rainfall, or may be concernod with weather types, solar influences, or with the interactions of atmosphere and ocean. Climatological probabilities and porsistence tendencies must also be taken into account.

Another of the favoured methods makes use of analogous situations from the past, and assumes that an existing weather situation will develop in the manner followed by a similar previous situation found in weather records. The finding of analogues is essentially the basis of the British mothod, which compares present and past patterns of temperature anomalies over a large part of the northern hemisphere, and also examines the sequence of weather charts during the month over the British Isles as well as the monthly mean pressure chart over the northern hemisphere. A forecast can then be made when a number of analogous situations lead to similar sequels. If their sequels are different, then the most likely sequel is chosen in the light of additional arguments which may be based on the limits of the polar ice-cap, sea temperatures, snow cover or some marked anomaly of the general circulation.

Other methods depond on extrapolation. For example, the United States Weather Bureau examines mean circulation patterns and extrapolates these by normal forecasting mothods, thus obtaining an indication of the most likely main paths of depressions and anticyclones during a period. From this indication can be produced charts showing anomalies of temperature and rainfall. Other extrapolation methods make use of periodogram analysis and extrapolate any regular variations found in a chosen predictor, though some methods used in the United States make use of a theoretical formula for obtaining the spood of movemont of a wave pattern.

Many of the methods are adaptable to the electronic computer, and the enormous possibilities of modern computing are causing somo roconsidoration of provious ideas on the use of statistical data. The computer also makes possible various researches on the use of dynamical theory to obtain a numerical prediction. 